\title{
SACAROSE, SUAS PROPRIEDADES E OS NOVOS EDULCORANTES
}

MANHANI, Tatiana Monique; CAMPOS, Maria Valéria M.; DONATI, Fulviane Pimentel. Discentes do Curso de Pós-Graduação em Controle de Qualidade dos Alimentos pelo Centro Universitário de Araraquara

(UNIARA). E-mails: tati.manhani@gmail.com; mariavaleria.campos@yahoo.com.br; fulvianepimentel@yahoo.com.br.

MORENO, Andréia de Haro. Pós-Doutora e docente do Centro Universitário de Araraquara (UNIARA). E-mail: ahmoreno@uniara.com.br.

\section{RESUMO}

O presente artigo tem como objetivo uma revisão da literatura sobre a sacarose, popularmente conhecida como açúcar de mesa; relatar como ela surgiu no Brasil e no mundo; discutir as diferenças entre a sacarose refinada e cristal; mostrar os malefícios do consumo excessivo; e relacionar seus principais edulcorantes. A sacarose surgiu há mais de 7 mil anos e desde então tem participado ativamente da criação de novas formas de consumo de alimentos, na construção de sociedades e nas relações sociais e políticas. Os carboidratos são a principal fonte de energia do organismo e, como eles se encontram presentes em diferentes alimentos, o seu consumo em excesso pode causar doenças como obesidade e diabetes. Aquantidade de produtos industrializados com sacarose em sua composição é incontável e o consumo excessivo tem causado preocupação em toda a área médica no mundo inteiro. A fabricação do açúcar é um processo que envolve uma série de operações até a obtenção do produto final. A sacarose possui variados tipos, que estão disponíveis de acordo com a sua utilização (doméstica e industrial). Os edulcorantes apresentam ação adoçante, podendo substituir a sacarose. Alguns desses compostos, conhecidos como edulcorantes intensos, sendo utilizados em quantidades muito pequenas, são direcionados a pessoas que apresentam algum distúrbio no metabolismo de açúcares (diabéticos) ou consumidores que estão em busca de produtos alimentícios de baixo valor calórico.

Palavras-chave: Sacarose; Propriedades; Edulcorantes.

\section{SUCROSE, ITS PROPRIETIES AND THE NEW SWEETENERS}

\begin{abstract}
The aims of this paper are to review the literature on sucrose, commonly known as table sugar; to report as it appeared in Brazil and in the world; to discuss the differences between crystal and refined sucrose; to show the harmful effects of overconsumption; and to list their main sweeteners. Sucrose appeared over 7000 years ago and since then it has actively participated in the creation of new forms of food consumption, in the development of societies and in the social and political relations. Carbohydrates are the main source of energy for the body and considering that they are present in different foods, their consumption in excess can cause diseasessuch as obesity and diabetes. The amount of processed products with sucrose in its composition is uncountable and overconsumption has caused concern in the medical field. The manufacture of sugar is a process that involves a series of operations to obtain the final product. There are several kinds of sucrose that are available according to its use (domestic and industrial). The sweeteners can be used to sweeten, and may replace sucrose. Some of these compounds are known as intense sweeteners, being used in very small quantities, are indicated to people who have adisorder in the metabolism of sugars (diabetics) or consumers who are in search of products of low calorific value.
\end{abstract}

KEYwORDS: Sucrose; Properties; Sweetners. 


\section{INTRODUÇÃo}

O presente artigo tem como objetivo uma revisão da literatura sobre a sacarose, popularmente conhecida como açúcar de mesa; relatar como ela surgiu no Brasil e no mundo, discutir as diferenças entre a sacarose refinada e cristal (as mais consumidas), os malefícios do consumo excessivo e relacionar os edulcorantes (adoçantes).

Este trabalho se justifica na necessidade de maior conhecimento sobre um produto tão comum na mesa do brasileiro, partindo dos efeitos da sua ingestão direta e também de alimentos industrializados que contenham o açúcar em sua composição, bem como sua história e edulcorantes.

Oriunda da cana-de-açúcar, a sacarose surgiu há mais de 7 mil anos e, desde então, tem participado ativamente da criação de novas formas de consumo de alimentos, na construção de sociedades, na mudança dos biomas e nas relaçõos sociais e políticas. Foi também responsável pela transformação do Brasil colonial, colocando-o como principal produtor e exportador de açúcar de cana no mundo, e como commodity vem influenciando economias em todo o globo devido ao seu alto valor comercial.

A produção brasileira de açúcar é, basicamente, a partir da extração do caldo da cana-de-açúcar (Sacharum officinarum), em um processo industrial que se baseia em moer, filtrar e ferver o caldo para, em seguida, centrifugar o melado, transformando-o em açúcar. Aadição de compostos químicos ao açúcar vai definir qual o tipo será produzido (OLÍMPIO, 2014).

Hoje, o açúcar é produzido em larga escala por diversos países, principalmente para fins alimentares, pois é umalimento natural e muito utilizado como ingrediente na indústria alimentícia. A quantidade de produtos industrializados com sacarose em sua composição é incontável e o consumo excessivo tem causado preocupação em toda a área médica, afinal ele está presente emrefrigerantes, sucos, bolos, biscoitos, tortas, inclusive em alimentos salgados, como molhos e massas, ou seja, em quase todos os alimentos que compõem a dieta de uma pessoa comum. Sem dúvida, o açúcar (sacarose) é um grande motivador de estudos e discussões, e baseado nisso, este trabalho foi idealizado.

\section{Metodologia}

A metodologia utilizada foi a pesquisa exploratória, ferramenta que possibilita a realização de um levantamento bibliográfico dos artigos sobre a temática, em sítios como Scholar Google, Scielo, revistas de história e especializadas, sites oficiais, livros, trabalhos e teses publicados entre 1973 e 2014 , utilizando as palavras-chaves: sacarose, malefícios e edulcorantes. Após o levantamento, as informações foram organizadas focando no objetivo da pesquisa e, ao final, serviram de base para a conclusão do trabalho.

\section{REVISÃo BiBLIOGRÁFICA \\ A origem do açúcar}

É impossível definir exatamente quando e onde a cana-de-açúcar surgiu no mundo. "Segundo pesquisas recentes, a Saccharum officinarum, espécie de cana dominante no mundo, é uma gramínea originária da região onde hoje se encontra a Papua Nova Guiné, na zona tropical do Oceano Pacífico, onde deve ter sido domesticada por populações tribais há mais de 7 mil anos" (PÁDUA, 2013, p.19). Há ainda variados estudos que defendem o seu surgimento na Polinésia, no entanto, como não há documentação que comprove o local de origem e nem o exato período, o seu surgimento é constantemente questionado. A única informação consensual de todos os estudos já realizados até hoje é a de que a planta tem origem asiática.

Séculos depois, a cana-de-açúcar foi encontrada na Índia e na China. "Não se sabe com precisão como se propagou na direção da Índia e da China, mas, por volta do século IV a.C., ela era cultivada nessas regiões, inclusive com a manufatura do açúcar em escala reduzida. No século III a.C., fabricava-se na China, a partir da cana, um produto sugestivamente identificado pelos ideogramas "pedra" e "mel"" (PÁDUA, 2013, p.19).

Muitos séculos depois, por volta do ano $600 \mathrm{~d}$. C., foram desenvolvidas as primeiras técnicas de refino de açúcar em uma universidade da Pérsia. Aideia era 
facilitar o estoque, transporte e comércio do produto, sem fermentá-lo. Com a conquista da Pérsia pelos exércitos árabes islâmicos, em 650 d. C., a receita do processamento do açúcar passou para os árabes, que assumiram o negócio e levaram mudas de cana para serem cultivadas nas terras conquistadas. Era o início da expansão do açúcar pelo mundo. As Cruzadas, que confrontaram muçulmanos e cristãos, também contribuíram para a difusão do produto pela Europa. Os cristãos tiveram contato com a "especiaria" no Oriente e continuaramusando-a quando voltaram para casa (OLÍMPIO, 2014).

Durante quase 500 anos, os centros consumidores de açúcar na Europa foram abastecidos por plantações e fábricas instaladas em regiões banhadas pelo Mediterrâneo, na própria Europa e no Norte da África. O desenvolvimento da produção canavieira na região do Mediterrâneo foi difundido a partir do Oriente Médio pelos árabes, instalando-se inicialmente nas ilhas e regiões peninsulares do sul da Europa e ao longo da costa da África do Norte (PIACENTE, 2010, p.35).

Com a expansão árabe no século X, entre Índia e Europa, a planta começou a se disseminar e o açúcar a ser produzido para um tímido mercado, voltado para fins medicinais e para o consumo de um público muito rico, ou seja, tornou-se um artigo de luxo.

O clima do Mediterrâneo até aceitou a aclimatação da cana, mas de forma limitada. Os colonizadores portugueses, em seu pragmatismo estratégico, aprenderam algumas lições sobre as restrições ecológicas de novos cultivos. (...) Com o tempo, eles se especializaram em introduzir nas colônias atlânticas espécies originárias dos trópicos asiáticos e africanos. O pleno florescimento da produtividade da planta ocorreu quando ela foi levada para ilhas como a Madeira e as Canárias e, depois, com muito maior intensidade, ao Brasil e ao Caribe (PÁDUA, 2013, p. 19-20).

\section{A introdução da cana-de-açúcar no Brasil}

Com a chegada da expedição colonizadora de Martin Afonso de Souza em 1532, por ordem do rei de Portugal, Dom João III, o Brasil foi dividido em Capitanias Hereditárias e então se fundou a vila São
Vicente, emSão Paulo. Nela foi construído um engenho denominado de São Jorge, que é reconhecido por alguns estudiosos como o primeiro do Brasil, ainda que outro, de nome São João, também figure como construído na mesma época e na mesma região (1533). Em 1534 consolidou-se a divisão do Brasil em Capitanias Hereditárias e, daí por diante, a cana se expandiu de modo crescente, enquanto todas as Capitanias consolidavam suas implantações através da formação de canaviais e de engenhos. Durante o Império, o país dependeu basicamente do cultivo da cana e da exportação do açúcar (CASTRO; KLUGE, 2001, apud MACHADO; HABIB, 2009).

Segundo Brandão (1985), inicialmente o cultivo da cana-de-açúcar no Brasil visava principalmente à fabricação de açúcar, com objetivo econômico para Portugal, sendo a principal fonte econômica oriunda da agricultura e a mais longa das bases econômicas de nossa história.

O ciclo econômico da cana-de-açúcar estendeuse da faixa litorânea de São Paulo até o Nordeste, e o cultivo era feito em morros, beiras de rios e em planícies, privilegiando as áreas que facilitassem a exportação do açúcar, ou seja, perto do oceano. Por questões lógicas, o início da monocultura canavieira no Brasil ficou limitado a algumas regiões litorâneas ou próximas ao litoral; isso se deu pelo fato de que, naquela época, os recursos tecnológicos, humanos e de logísticas para produção e exportação eram completamente limitados, além da dificuldade de exploração territorial para o preparo do plantio em regiões afastadas do litoral (THEODORO, 2011, p.13).

De acordo com Rosseto (2008), a atividade canavieira no século XVI ocupava terras férteis e, para facilitar a exportação do açúcar para a Europa, expandiu-se estrategicamente em 14 regiões litorâneas do Nordeste, o que facilitaria seu comércio. Por esse motivo, o bioma mais prejudicado na época foi o da Mata Atlântica, que foi praticamente dizimada pela ocupação canavieira.

E o impacto nas florestas não se devia apenas à abertura de terras para o plantio. Para cada quilo de açúcar produzido, cerca de 15 quilos de lenha eram 
queimados nas fornalhas, que alimentavamos enormes caldeirões onde o caldo da cana era cristalizado. Para purgar o açúcar nas moendas, utilizava-se cinza de madeira, em muitos lugares retirados dos manguezais. Das árvores tropicais provinham até as caixas onde o açúcar era acondicionado para exportação (PÁDUA, 2013, p.21).

Como em qualquer atividade econômica, a atividade canavieira proporcionou ao Brasil um início de crescimento econômico, apesar da exploração de outros recursos e da dificuldade de desbravar outras áreas para o plantio, tendo em vista que a área plantada era insignificante em relação ao tamanho do país (THEODORO, 2011, p.13).

O crescimento econômico da colônia, advindo da atividade canavieira, sustentou-se não somente pela exploração de recursos ambientais abundantes naquele tempo, mas também pela força de trabalho inicialmente indígena e, posteriormente, africana. Desse modo, o açúcar também colaborou para impulsionar a escravidão no Brasil.

Segundo Schwartz (2013 p.24-25), na primeira metade do século da produção brasileira, os povos nativos (indígenas) foram contratados ou forçados a trabalhar no campo, mas a relutância de guerreiros em trabalhar na agricultura, as doenças epidêmicas da década de 1560, as guerras de resistência, as leis reais contra a escravização dos indígenas (de 1570, 1595 e 1609), além dos esforços dos jesuítas que exigiam um tratamento mais digno para os índios, tornaram muito caro e difícil o uso de trabalhadores indígenas. A resposta veio da África. Os escravos africanos eram caros, mas os portugueses acreditavam que eles eram mais produtivos que os índios, e menos propensos a fugir ou morrer de doenças. "Sem açúcar, não há Brasil; sem a escravidão, não há açúcar; sem Angola, não há escravos", era um dito comum que mostrava a centralidade do açúcar, da escravidão e da África para a existência da colônia.

O ciclo evolutivo da cultura da cana-de-açúcar no Brasil, apresentada ao longo dos séculos, garantiu uma importância crucial em face ao desenvolvimento econômico nacional. A produção do açúcar no período colonial, perpendicularmente à extração de metais e pedras preciosas, garantiu à metrópole portuguesa 0 acúmulo fulminante e ininterrupto de riquezas, com a fomentação de sua comercialização por todo o mundo (ARAÚJO; SANTOS, 2013).

O Brasil colonial não nasceu do açúcar, mas do pau-brasil. Foi a famosa madeira, da qual se extrai um corante, que primeiro deu motivos aos portugueses para se estabelecerem explorar a terra a que tinham chegado em 1500. Porém, foi a introdução da canade-açúcar e dos engenhos, com sua tecnologia para produção de açúcar, a verdadeira responsável por transformar a colônia três décadas depois desse primeiro contato. O açúcar foi a madrasta da colonização, que por quase dois séculos regeu a história econômica, social e política do Brasil (SCHWARTZ, 2013, p.22).

\section{SACARose (açúcar de mesa)}

$\mathrm{O}$ açúcar é um termo genérico utilizado para carboidratos cristalizados comestíveis, sendo encontrado na forma de sacarose, lactose e frutose (OLÍMPIO, 2014).

Os carboidratos são abundantes na natureza, compreendendo mais de $90 \%$ da matéria seca das plantas. Eles podem ser obtidos de várias fontes renováveis, ocorrem em diversas estruturas e graus de polimerização, apresentam variadas propriedades físicas e químicas, são suscetíveis a modificações físicas e químicas e são biodegradáveis. Estão presentes nos alimentos como constituintes naturais ou podem ser ingredientes aditivos (OETTERER; SARMENTO, 2006, p.135).

Pertencem a esse grupo substâncias como glicose, frutose e sacarose, responsáveis pelo sabor doce de vários alimentos, amido, principal fonte de reserva de alguns tecidos vegetais, e a celulose, o carboidrato mais abundante da natureza e principal componente de tecidos vegetais (RIBEIRO; SERAVALLI, 2004, p.32). Neste trabalho, a substância escolhida para discussão é a sacarose.

A sacarose é constituída de duas moléculas, uma de frutose e uma de glicose; em outras palavras, é um 
dissacarídeo, ou seja, um composto formado pela união de dois monossacarídeos: a glicose e a frutose (REVISTAADITIVOS E INGREDIENTES, 2011, p.34).

Francisco Jr. (2008, p.09) enfatiza que a sacarose é hoje no Brasil um dos mais importantes produtos, devido à produção do álcool combustível, cuja obtenção se dá também por fermentação. A primeira etapa é a hidrólise da sacarose, da qual se obtém uma mistura de glicose e frutose, também conhecida por açúcar invertido, comumente utilizado na fabricação de doces, para evitar a cristalização da sacarose e conferir maior maciez ao doce.

Segundo Oetterer e Sarmento (2006, p. 145), a sacarose é natural em diversos vegetais, como pêssego (7\%), abricó $(5,8 \%)$, beterraba $(6,1 \%)$, cenoura $(4,2 \%)$ e melão $(5,7 \%)$. Comercialmente é extraída da cana de açúcar, que pode conter de $14 \%$ a $24 \%$ de sacarose, ou da beterraba. A sacarose forma soluções altamente concentradas, de elevado poder osmótico (efeito preservativo e umectante) e tem função crioprotetora em alimentos.

O açúcar é o adoçante mais versátil de todos os que estão disponíveis. Seu uso é comum em uma variedade de alimentos muito grande, devido a seus muitos atributos, que não podem ser duplicados por nenhum outro ingrediente (REVISTAADITIVOS E INGREDIENTES, 2011, p.39).

\section{O processo de obtenção da sacarose}

A fabricação do açúcar é um processo que envolve uma série de operações até a obtenção do produto final. De uma maneira simplificada, para se obter a sacarose, a cana-de-açúcar passa pelas seguintes etapas:

- Lavagem da cana: a cana-de-açúcar, chegando às usinas em sua forma pura, é colocada em uma esteira rolante. Lá, ela é submetida a uma lavagem que retira sua poeira, areia, terra e outros tipos de impurezas. Na sequência, a cana é picada e passa por um eletroímã, que retira materiais metálicos do produto (NOVACANA, 2014).

- Extração do caldo (moagem ou difusão):

O Por moagem: a moagem consiste na extração do caldo que contém a sacarose mediante sucessivas passagens da cana já desfibrada, no processo de preparo, entre pares de rolos cilíndricos que a espremem, separando o caldo da fibra (GONÇALVES, 2013).

O Por difusão: a difusão é um fenômeno osmótico pelo qual uma solução migra para outra de concentração diferente, através de uma membrana permeável à solução. A sacarose é extraída em contracorrente com o caldo diluído e a água; a cana-de-açúcar desfibrada entra em uma extremidade do aparelho e na outra sai esgotada, sendo conduzida para moendas em prensas especiais para secar o bagaço, que será enviado às caldeiras com 50\% de umidade (SOUZA, 1995).

- Purificação do caldo: Delgado; Cesar, 1977, apud Lima, 2012, p. 23 afirmam que o caldo de canade-açúcar extraído contém impurezas grosseiras, tais como: bagaços, pedaços de cana-de-açúcar, areia e terra, que são removidos por peneiras. A remoção dessas peneiras se faz necessária antes que se passe a fase de clarificação, pois as mesmas promovem frequentes entupimentos de bombas, propiciando incrustações em tubulações dos corpos aquecedores e evaporadores. Várias são os tipos de peneiras utilizadas na prática da remoção de impurezas grosseiras presentes no caldo e podem ser reunidas em três tipos básicos: fixas (Cush-Cush e DSM), vibratórias e rotativas.

- Clarificação do caldo: a clarificação do caldo de cana-de-açúcar ocorre através da coagulação, floculação e precipitação dos coloides e substâncias corantes eliminadas por decantação e filtração, ou seja, forma-se um precipitado insolúvel que absorve e arrasta as impurezas do caldo. A floculação pode ser obtida por uma mudança de $\mathrm{pH}$ do meio, utilizando-se reagentes químicos e pelo aquecimento (LEITÃO, 1973). A clarificação do caldo envolve basicamente as etapas de sulfitação (contato contracorrente do caldo e dióxido de enxofre), calagem (o caldo recebe leite de cal), e/ou adição de compostos poliméricos de cadeia longa, sendo o caldo aquecido e ocorrendo a decantação e, consequentemente, a formação do caldo clarificado que segue para a etapa de 
concentração (TFOUNI et al., 2007).

- Evaporação do caldo: a evaporação do caldo é feita para que a concentração do xarope fique entre 60 e $70^{\circ}$ Brix, sendo recomendado $65^{\circ}$ Brix (valor do teor de sólidos solúveis contidos no caldo). Aquantidade de água removida na evaporação é cerca de $80 \%$ em peso do caldo ou aproximadamente $70-80 \%$ do peso da cana (ANDRADE; CASTRO, 2006, apud MEZAROBA; MENEGUETTI; GROFF, 2010).

- Cozimento: o caldo de cana, após tratamento físico-químico, é concentrado nos evaporadores até a fase de xarope, com concentração de $60^{\circ}$ a $70^{\circ}$ Brix, e juntamente com os méis reciclados no processo, são enviados ao setor de cozimento, onde ocorre o fenômeno de formação e crescimento dos cristais de sacarose por evapocristalização. O processo de cozimento pode ser feito com 2 a 3 massas, com o objetivo de se esgotar o açúcar contido no mel final, a ser enviado à destilaria para produção de álcool (TAMBELLINI, 2005, p.26).

- Cristalização da sacarose: Segundo Torres (2007, p.13), no início da operação dos cristalizadores batelada, uma porção inicial de xarope é concentrada até atingir um Brix pré-estabelecido. Nesse momento são injetados núcleos cristalinos de açúcar dentro do cristalizador. Ao longo da batelada, os núcleos vão crescendo até o tamanho desejado, através da contínua adição de xarope e do controle da evaporação. A essa suspensão formada por cristais, e por uma espécie de mel de alta viscosidade, dá-se o nome de massa cozida. Esse mel é chamado de licor-mãe, que é uma solução idealmente composta de sólidos solúveis e água. Nessa etapa, parte da sacarose da massa está constituindo os cristais e parte está dissolvida no licor-mãe. Todos os demais sólidos solúveis no licor que não sejam sacarose são chamados de impurezas. O cristalizador é geralmente conhecido por cozedor, cozedor a vácuo ou simplesmente vácuo.

- Centrifugação (separação entre cristais e massa cozida): o açúcar, agora na forma de cristais e presente na massa cozida, precisa ser separado do mel, que se encontra em estado líquido. A centrifugação é um processo de separação sólido/ líquido que utiliza a força centrífuga como agente separador. As centrífugas de açúcar, responsáveis por essa separação, são equipamentos formados por um cesto cilíndrico construído em chapa perfurada, montado com um eixo central em posição vertical e acionado diretamente por um motor elétrico, também em posição vertical, de rotação elevada (1200 rpm). Durante esse período, a força centrífuga comprime a massa cozida contra a tela de aço, que só permite a passagem da parte líquida, o mel, e retém os cristais de açúcar que são maiores que os orifícios da mesma (SILVA, 2007, p.36).

- Secagem: a operação de secagem do açúcar consiste basicamente na redução de sua umidade e pelo resfriamento simultâneo, a níveis que permitam sua armazenagem por períodos mais ou menos longos, sem apresentar alterações significativas de suas características, isto é, preservando sua qualidade para consumo como produto alimentício (ACKERMANN, 2005, p.28). Os cristais de açúcar separados na centrifugação seguem para a secagem. O açúcar úmido passa por dentro de tambores rotativos, os chamados secadores, nos quais o ar quente e ar frio são utilizados para secar e resfriar o açúcar. Uma vez seco, o açúcar pode seguir para o ensaque, ou pode ser utilizado na produção de outros tipos de açúcar (TORRES, 2007, p.15).

\section{Sacaroses: refinada e cristal}

A sacarose possui variados tipos, que estão disponíveis de acordo coma sua utilização (doméstica ou industrial), tais como açúcar refinado, cristal, confeiteiro, mascavo, invertido, líquido, etc.; porém, os mais adquiridos pelo consumidor comum são os açúcares refinado e cristal, especificados abaixo:

O cristal é o açúcar com cristais grandes e transparentes, relativamente difíceis de serem dissolvidos em água. Depois do cozimento, ele passa apenas por etapas de refinamento, as quais retiram cerca de $90 \%$ dos sais minerais. Por ser econômico e render bastante, o açúcar cristal sempre aparece nas receitas de bolos e doces (CHEMELLO, 2005, p.13).

Conforme citado no artigo "Evolução do Açúcar", da "Revista Aditivos e Ingredientes" (2011), o açúcar 
cristal possui elevada gama de aplicações industriais e menor custo de aquisição em relação aos demais tipos de açúcares. Um açúcar cristal de boa qualidade apresenta de $99,5 \%$ a $99,8 \%$ de sacarose; $0,03 \%$ a $0,10 \%$ de glicose e frutose; $0,05 \%$ a $0,10 \%$ de umidade; e $0,04 \%$ a $0,10 \%$ de sais minerais.

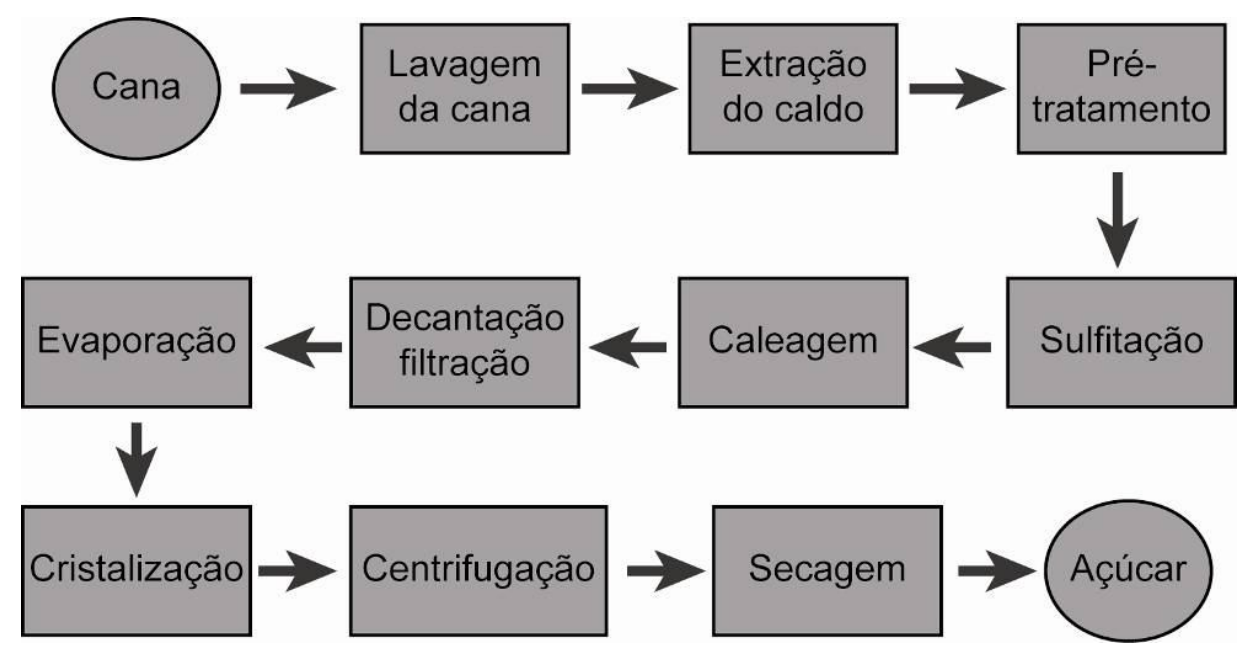

Figura 1 - Fluxograma do processo de tratamento do caldo de uma unidade produtora de açúcar cristal Fonte: SeaD/UFSCAR.

O açúcar refinado, também conhecido como açúcar branco, é o açúcar mais comum nos supermercados. No refinamento, aditivos químicos, como o enxofre, tornam o produto branco e delicioso. O lado ruim, segundo a maioria dos nutricionistas, é que este processo retira vitaminas e sais minerais, deixando apenas as "calorias vazias" (sem nutrientes), permanecendo cerca de 99,8\% de sacarose (CHEMELLO, 2005, p.13).
Mezaroba; Meneguetti; Groff (2010) acrescentam que, da parte mais fina da peneiração, é extraído o açúcar de confeiteiro e, do restante, o açúcar refinado. Ainda existe uma separação entre o açúcar refinado: 0 açúcar que possui cristais bem definidos e granulometria homogênea é chamado de açúcar refinado granulado e o açúcar com granulometria mais fina é titulado açúcar refinado amorfo.

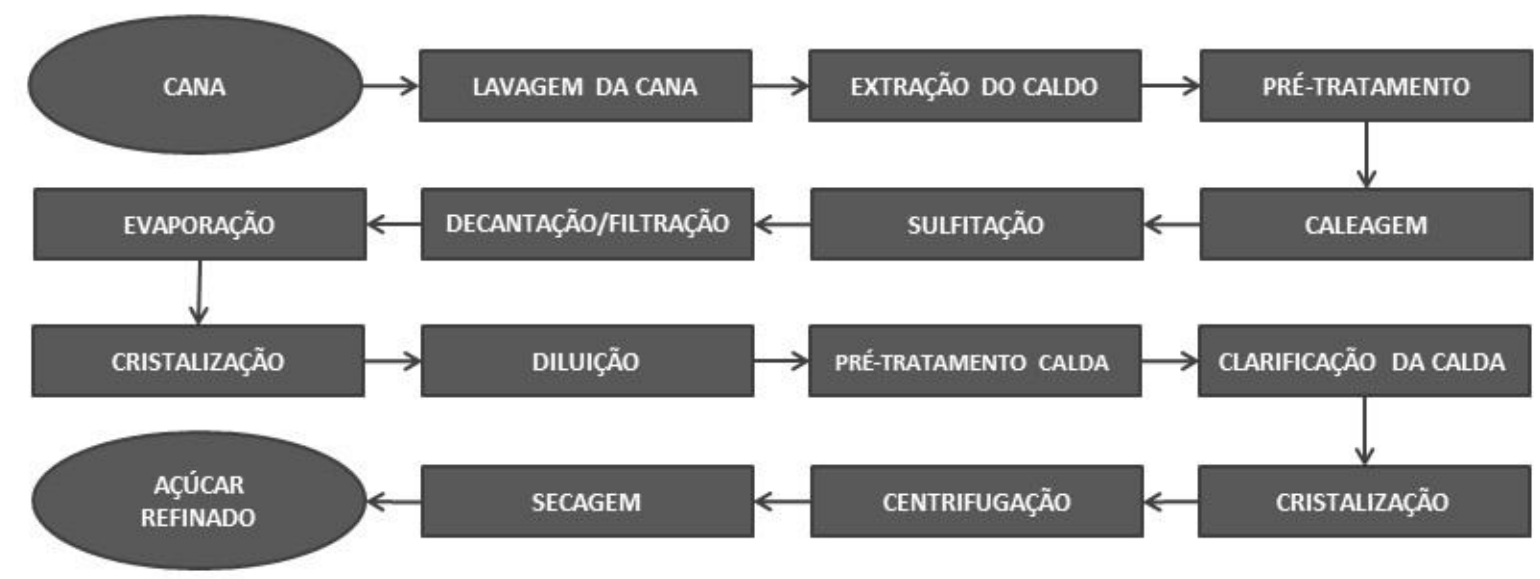

Figura 2 - Fluxograma do processo de tratamento do caldo uma unidade produtora de açúcar refinado.

Fonte: SeaD/UFSCAR. 
Como dito anteriormente, a utilização de cada tipo de açúcar depende do fim a que se destina. Da mesma maneira que os açúcares refinado e cristal são bastante utilizados diretamente, os outros tipos também o são pela indústria alimentícia. Cada tipo possui suas particularidades e também seus malefícios quando consumidos em excesso.

\section{Malefícios do CONSUMO EXCESSIVo do AÇÚCAR}

Os carboidratos são a principal fonte de energia do organismo. Como eles se encontram presentes em diferentes alimentos, o seu consumo em excesso pode causar doenças como obesidade e diabetes (CRUZ; SARTI, 2011).

Um estudo divulgado por pesquisadores da Universidade da Califórnia adicionou mais um prejuízo à saúde ao vasto repertório de problemas trazidos pelo consumo de açúcar: além de aumentar os riscos de doenças como o diabetes tipo 2, ele também pode atrapalhar o aprendizado e a memória. Pesquisadores conseguiram provar em laboratório que o alto consumo de frutose, um tipo de açúcar, diminuiu o número de conexões entre as células nervosas de ratos (YARAK, 2012).

$\mathrm{O}$ açúcar é rico em calorias e pobre em nutrientes, motivos pelos quais se deve restringir ainda mais seu consumo. O excesso é a causa de uma série de problemas, muito além das cáries. A obesidade já é considerada uma questão de saúde pública, tamanha a quantidade de pessoas que sofrem da doença. Outro ponto negativo é a sobrecarga no pâncreas para produção de insulina (o pâncreas é órgão responsável pela produção de insulina), que mantém os níveis de glicose controlados no sangue. Essa deficiência pode levar ao diabetes tipo 2. O aumento do nível de triglicérides também é um ponto negativo a ser considerado, pois o consumo exagerado do açúcar pode contribuir na elevação no nível de triglicérides, gordura perigosa, que ao se acumular pode obstruir as artérias. $\mathrm{O}$ resultado pode ser a maior chance de desenvolver doenças cardiovasculares (SOCIEDADE BENEFICENTE ISRAELITABRASILEIRA, 2007).

Ao longo da história, o homemobteve quantidades limitadas desse alimento, por meio de frutas ou mel. $\mathrm{O}$ consumo anual, no final do século XIX, por exemplo, era de apenas 2 quilos por pessoa. Atualmente é de 37 quilos, segundo Michel Raymond, pesquisador do Instituto de Ciências Evolutivas da Universidade de Montpellier, na França. Essa mudança drástica não deixou o organismo humano impune. Estudos mostram que o açúcar, por alterar alguns tecidos humanos durante a fase de crescimento, pode ser o responsável por problemas que vão de miopia e acne até o câncer (YARAK, 2012).

Em 2003, a World Health Organization preconizou que a ingestão de açúcar não superasse $10 \%$ do total energético diário. Em 2005, a American Dietary Guidelines recomendou a diminuição do consumo de alimentos ricos em açúcares de adição, limitando o total de energia para proporções entre $8 \%$ e $20 \%$, dependendo do total energético gasto por indivíduo. O Institute of Medicine, por meio das Dietary Reference Intakes, recomendou que a maior parte da energia deve ser obtida a partir do total dos grupos de alimentos e menor conteúdo energético deve estar disponível para o uso em forma de açúcares de adição (GAINO; SILVA, 2011, p. 95-96).

Uma nova orientação da Organização Mundial de Saúde (OMS) propõe que a quantidade diária de açúcar na alimentação seja reduzida à metade. Antes, do consumo total de calorias ingeridas, $10 \%$ poderia ser de açúcar. Agora, basta 5\%, inclusive de açúcares adicionados, aqueles colocados nos alimentos industrializados durante o processamento (CONSELHO FEDERAL DE NUTRICIONISTAS, 2014).

A quantidade ideal de consumo do açúcar ainda é controversa. A Associação Americana do Coração indica que mulheres consumam no máximo seis colheres de chá de açúcar por dia (30 gramas ou 100 calorias). Para os homens, o limite seria de nove colheres de chá (45 gramas ou 150 calorias). Em 2009, quando a recomendação foi publicada, o americano consumia em média 22 colheres de chá de açúcar todos os dias - o Brasil não tem estimativas seguras, mas, calculase, com base em dados da Companhia Nacional de Abastecimento, órgão vinculado ao Ministério da 
Agricultura, algo em torno de 150 gramas por dia, ou 30 colheres de chá (YARAK, 2012).

Pesquisas envolvendo intervenções de longo prazo e nas quais sejamempregadas quantidades de açúcares normalmente ingeridas pelos indivíduos são necessárias e podem preencher a lacuna de informações sobre o tema. Políticas públicas poderiam contribuir para a definição e monitoramento, visando limitar o consumo dos alimentos ricos em açúcares de adição. Para a população, devem ser fornecidos subsídios para que realizem escolhas alimentares mais saudáveis, o que contribuiria para o alcance da segurança alimentar e nutricional (GAINO; SILVA, 2011, p. 88).

\section{EDULCORANTES}

O consumo de light e "diet" vem aumentando consideravelmente nos últimos 20 anos. Esses produtos são direcionados a pessoas que apresentam algum distúrbio no metabolismo de açúcares (diabéticos) ou consumidores que estão em busca de produtos alimentícios de baixo valor calórico. A indústria de alimentos utiliza a mistura de edulcorantes artificiais para propiciar um efeito sinérgico, que possibilita empregálos em menores quantidades, resultando em redução de custo e melhoria de atributos sensoriais. Existe uma grande variedade de produtos destinados à restrição ou redução de carboidratos, destaque aos adoçantes de mesa (TOZETTO; DEMIATE; NAGATA, 2007).

Os edulcorantes apresentam ação adoçante, podendo substituir a sacarose. Alguns desses compostos são conhecidos como edulcorantes intensos, sendo utilizados em quantidades muito pequenas. Geralmente são não-nutritivos ou pouco calóricos e não apresentam ação carcinogênica. Dentre os edulcorantes que não são metabolizados pelo organismo, não fornecendo energia, estão a sacarina, cujo poder edulcorante é cerca de 300 vezes a da sacarose, sendo frequentemente de gosto residual; o ciclamato, de 30 a 50 vezes mais doce que a sacarose, apresenta sabor residual agridoce desagradável; acesulfame-k, cerca de 180 a 200 vezes mais doce do que a sacarose, tem doçura semelhante à da glicose; e a sucralose, obtida a partir do açúcar comum, poder edulcorante pode variar de 400 a 800 vezes em relação à sacarose. Os edulcorantes nutritivos fornecem quantidades variadas de energia, porém contribuem para a redução do valor energético dos alimentos, como é o caso do aspartame, que tem valor calórico igual ao da sacarose (4 kcal/g), só que é utilizado em quantidade mínima devido a sua intensa doçura (cerca de 180 vezes a da sacarose), o que proporciona diminuição no teor calórico. Pode ser consumido por diabéticos, mas não por portadores de fenilcetonúria, doença genética que altera o metabolismo da fenilalanina (MILAGRES et al., 2010, p.440).

Sacarina e ciclamato são os edulcorantes que surgiram há mais tempo, e são os mais econômicos disponíveis no mercado. O aspartame, apesar de apresentar o menor sabor residual, tem sua estabilidade limitada em ácidos e processamentos térmicos, não sendo, portanto, tecnologicamente adequado para alguns produtos ou situações de consumo (CASTRO; FRANCO, 2002). Vários adoçantes comercializados contêm dois ou mais edulcorantes em suas fórmulas. Segundo os fabricantes, essa mistura visa potencializar as vantagens de cada edulcorante e neutralizar desvantagens, principalmente o sabor residual (TORLONI et al., 2007, p.268).

A sacarina, o primeiro adoçante artificial, foi descoberto acidentalmente em 1879 por Constantino Fahlberg e é usado nos Estados Unidos desde 1901. A substância, um derivado da naftalina 400 vezes mais doce do que o açúcar, é lentamente absorvida pelo trato intestinal e rapidamente excretada pelos rins, sem ser metabolizada. Usada em concentrações muito altas, o adoçante tem sabor amargo, por isso passou a ser associado a outros edulcorantes, a partir de 1950, com a descoberta do ciclamato (TORLONI et al., 2007, p.269). Em 1984 foi estabelecido um valor de ingestão diária aceitável, que é de $2,5 \mathrm{mg} / \mathrm{kg}$ de peso corpóreo do consumidor. A sacarina é proibida em alguns países, pois existem dúvidas sobre o seu caráter carcinogênico (ASSUMPÇÃO et. al., 2008, p.1743).

Ciclamato de sódio foi descoberto em 1937 nos Estados Unidos; apesar de ser 30 a 50 vezes mais doce que o açúcar, é menos intenso; para aumentar seu poder, 
mistura-se com sacarina. $\mathrm{O}$ aspartame foi descoberto em 1935, é de 180 a 200 vezes mais doce que o açúcar, apresenta $4 \mathrm{Kcal} / \mathrm{g}$. A sucralose foi descoberta em 1976 , sendo 600 vezes mais doce que o açúcar, não contém valor energético (DURAN et al., 2011).

A estévia é um edulcorante natural, usado na medicina curativa do Paraguai, sendo 300 vezes maior que a sacarose e não contém calorias (DURAN et al., 2011). Foi aprovada no Brasil em meados de 1987, como agente flavorizante e edulcorante em várias classes de alimentos; nos Estados Unidos, em 1996, para ser utilizado como ingredientes para suplemento dietético (GOTO, 1998).

Em um estudo realizado, 76,7\% dos pacientes usavam adoçante pela presença do Diabetes Melito e o não uso do adoçante pelo seu sabor desagradável. Foi determinado também que o consumo é maior em idosos do que nos adultos e maior no sexo feminino, cerca de 63,6\% (OLIVEIRA; FRANCO, 2010, p.458). O edulcorante mais aceitável apresenta sabor e propriedades funcionais semelhantes aos da sacarose (FERNANDES et al., 2009, p.359).

Os adoçantes são compostos por substâncias edulcorantes (que adoçam) e por umagente de corpo que confere durabilidade, boa aparência e textura ao produto final (TORLONI et al., 2007, p.268). Em medicamentos, segundo Balbani; Stelzer e Montivani (2006, p.402), o aspartame, o ciclamato de sódio e a sacarina sódica podem induzir reações de hipersensibilidade, aparecendo urticária, prurido e angioedema. Há possibilidade de reação alérgica cruzada entre a sacarina, o aspartame e as sulfonamidas.

Um mesmo edulcorante que deixa a percepção de um gosto residual amargo intenso em um produto, pode ter essa característica atenuada em outro produto com outra estrutura química, e isso pode acontecer em diferentes temperaturas. $\mathrm{O}$ aumento da temperatura geralmente causa o enfraquecimento, ou até mesmo a quebra das pontes de hidrogênio intramolecular nos açúcares, as quais afetam o estímulo doce, os alternado com o amargo (CARDOSO; BATTOCHIO; CARDELLO, 2004).

Em outro estudo, Cardoso; Battochio e Cardello
(2004) verificaram que ocorreram diferenças sensoriais importantes em função da temperatura, pois, enquanto para o aspartame e para a mistura ciclamato/sacarina 2:1 o aumento de temperatura provocou diminuição no poder edulcorante, para a estévia e para a sucralose foi observado o aumento no poder edulcorante; contudo, não se pode generalizar, pois tudo depende do poder edulcorante em função da temperatura, podendo variar em função da classe química e da dispersão em que se encontra.

\section{Considerações finais}

Por meio da pesquisa realizada para a elaboração deste artigo, foi possível rever a trajetória da cana-deaçúcar desde o seu surgimento na região da Papua Nova Guiné até o início das plantações no Brasil. Através dessa revisão da história, conclui-se que o plantio da cana-de-açúcar e o próprio açúcar tiveram um importante papel na transformação da sociedade e economia brasileira, e da mesma maneira influenciou o restante do mundo.

Consolidado como um dos principais commodities, item imprescindível na indústria alimentícia e produto dos mais presentes na mesa das pessoas, o açúcar atualmente vem sendo taxado como vilão da saúde, devido ao alto índice de doenças (diabetes tipo 2, obesidade, triglicérides) advindas do consumo excessivo mesmo que indireto, pois está presente em uma infinidade de produtos da dieta humana. Por isso, há tantas discussões a respeito da redução de quantidades ingeridas e até mesmo a substituição do produto por outros com a intenção de minimizar os efeitos do consumo.

A substituição da sacarose pelos edulcorantes tornou-se uma alternativa para aqueles indivíduos que precisam reduzir o consumo, como no caso dos portadores de diabetes. No entanto, a procura também é grande por aqueles que estão buscando apenas obter uma alimentação menos calórica.

\section{REFERÊNCIAS}

ARAÚJO, E., SANTOS, J. O desenvolvimento da 
Sacarose, suas propriedades e os novos edulcorantes

cultura da cana-de-açúcar no Brasil e sua relevância na economia nacional. Revista Científica Facider, n.4, set. 2013. Disponível em: <http://seicesucol.edu.br/revista/index.php/facider/article/view/ 37>. Acesso em: 19 mar. 2014.

ACKERMANN, H. P. H. Secagem do açúcar. Revista Opiniões, n. 6. p. 28. Out/Dez. 2005.

ASSUMPÇÃO M.H.M.T. et al. Desenvolvimento de um procedimento biamperométrico para determinação de sacarina em produtos dietéticos. Química Nova, v. 31, n. 7, p. 1743-1746, ago. 2008.

A EVOLUÇÃO do Açúcar. Revista Aditivos e Ingredientes, n. 82, p.34-39, set. 2011.

BALBANI A.P.S.; STELZER L.B.; MONTIVANI J.C.; Excipientes de medicamentos e as informações da bula, Rev. Bras. Otorrinolaringologia v. 72, n. 3, p. 400-406, maio/jun. 2006.

BRANDÃO, A. Cana-de-açúcar: álcoole a açúcar na história e no desenvolvimento social do Brasil. Brasilia: Horizonte, 1985.

CARDOSO J.B.P.; BATTOCHIO J.R.; CARDELLOH.M.A.B.; Equivalência de dulçor e poder edulcorante de edulcorantes em função da temperatura de consumo em bebidas preparadas com chá-mate em pó solúvel, Ciência e Tecnologia de Alimentos, v. 24, n. 3, p. 448-452, jul./set. 2004.

CASTRO, P.R.C.; KLUGE, R.A. (ed). Ecofisiologia de culturas extrativas: cana-deaçúcar, seringueira, coqueiro, dendezeiro e oliveira. Cosmópolis: Ed. Stoller do Brasil. 2001. $138 \mathrm{p}$.

CASTRO A.G.P.; FRANCO L.J.; Caracterização do consumo de adoçantes alternativos e produtos dietéticos por indivíduos diabéticos, Arq. Bras.
Endocrinol. Metal., v. 46, n. 3, p. 280-287, jun. 2002.

CHEMELLO, E. A. Química na cozinha apresenta: o açúcar. Revista Eletrônica Zoom da Editora Cia da Escola. Ano 6, n. 4, 2005. Disponível em: <http://www.ciadaescola.com.br/zoom/ materia.asp?materia=291 > Acesso em: 08 mar. 2014

\section{CONSELHO FEDERAL DAS}

NUTRICIONISTAS. Saiba como identificar e evitar o açúcar nos rótulos dos alimentos. Mar. 2014. Disponívelem: <http://www.cfn.org.br/ eficiente/sites/cfn/ptbr/ site.php?secao=nutricaonamidia\&pub=1858> Acesso em: 10 abr. 2014.

CRUZ, S. H. da.; SARTI, D. A. A química do açúcar. Dez, 2011. Disponível em: http:// crq4.org.br/?p=texto.php\&c=quimicaviva_acucar $>$ Acesso em: 10 abr. 2014.

DURÁN, Samuel et al. Niveles de ingesta diária de edulcorantes no nutritivo em escolares de la región de Valparaíso, Rev. Chil. Nutri., vol. 38, n. 4, dez. 2011.

FERNANDES A.G. et al. Avaliação sensorial de bebidas de goiaba adoçadas com diferentes agentes adoçantes, Ciência e Tecnologia de Alimentos, v. 29, n. 2, p. 358-364, abr./jun. 2009.

FRANCISCO JR, W. E. Carboidratos: estrutura, propriedades e funções. Química Nova na Escola, n. 29, ago. 2008.

GAINO, N. M.; SILVA, M. V. da. Consumo de frutose e impacto na saúde humana. Segurança Alimentar e Nutricional, Campinas, v. 18, n. 2, p. 88-98, jul. 2011.

GONÇALVES, R. G. M. Processo de Extração 
de Caldo por Moendas. Julho, 2013. Disponível em: <http://tecsucro.blogspot.com.br/2013/07/ processo-de-extracao-de-caldo-por.html $>$ Acesso em: 02 abr. 2014.

GOTO A.; CLEMENTE E.; Influência do rebaudiosídeo A na solubilidade e no sabor do esteviosídeo, Ciência e Tecnologia de Alimentos, v. 18, n.1, jan./abr. 1998.

LEITÃO, M. F. F. Microbiologia de sucos e produtos ácidos. Boletim do Instituto de Tecnologia de Alimentos, Campinas, n.33, p. 942, 1973.

LIMA, R. B. Processo de clarificação do caldo de cana- de- açúcar aplicando elétrons acelerados. $61 \mathrm{f}$. Dissertação (Mestrado) Instituto de Pesquisas Energéticas e Nucleares, São Paulo, 2012.

MACHADO, L.A.; HABIB, M. Perspectivas e impactos da cultura de cana-de-açúcar no Brasil. 2009. Artigo em Hypertexto. Disponível em: <http:// www.infobibos.com/Artigos/2009_2/Cana/ index.htm>. Acesso em: 08 mar. 2014.

MEZAROBA, S.; MENEGUETTI, C. C.; GROFF, A. M. Processos de produção do açúcar e os possíveis reaproveitamentos dos subprodutos e resíduos resultantes do sistema. In: ENCONTRO DE ENGENHARIA DE PRODUÇÃO AGROINDUSTRIAL, 4. - FECILCAM. Campo Mourão, 17-19 nov. 2010.

MILAGRES M.P. et al. Análise físico química e sensorial de doce de leite produzido sem adição de sacarose. Rev. Ceres, v. 57, n. 4, p. 439-445, jul/ ago. 2010.

NOVACANA.COM. Processos de fabricação do etanol. Disponível em: <http://www.novacana.com/ etanol/fabricacao/ > Acesso em: 02 abr. 2014.
OLÍMPIO, J. A. O açúcar do Brasil. Teresina, 2014. Disponívelem: <http://www.sinterpi.org.br/ artigos/o-acucar-do-brasil/> Acesso em: 12 mar. 2014.

OLIVEIRAP.B.; FRANCO L.J.; Consumo de adoçantes e produtos dietéticos por indivíduos com diabetes melito tipo 2, atendidos pelo Sistema Único de Saúde em Ribeirão Preto, S/P, Arq. Brás. Endócrino. Metab., v. 54, n.5, p. 455-462, abr. 2010.

OETTERER, M. SARMENTO. S. B. S. Propriedades dos açúcares. In: OETTERER, M.; BISMARA, M. A.; D'ARCE, R.; SPOTO, M. H. F. Fundamentos de Ciência e Tecnologia de Alimentos. Barueri: Ed. Manole, 2006. Cap. 4, p.136-145.

PÁDUA, J. A. O amargo avanço da doçura. Revista de História da Biblioteca Nacional, ano 8, n. 94, p.19-21, jul. 2013.

\section{PIACENTE, F. J. Inovação e trajetórias} tecnológicas: o caso dos dois sistemas para extração da sacarose no Brasil. 199 f. Tese (Doutorado) - Universidade Estadual de Campinas, Campinas, 2010.

PORTOGENTE - TRANSPORTE E LOGÍSTICA. Do plantio à exportação de açúcar. Abril, 2006. Disponível em: <http://portogente.com.br/noticias/ transporte-logistica/do-plantio-a-exportacao-deacucar-6270 > Acesso em: 02 abr. 2014.

RIBEIRO, E. P.; SERAVALLI, E. A. G. Química de alimentos. São Paulo: Ed. Edgard Blücher: Instituto Mauá de Tecnologia, 2004. p.32.

ROSSETO, R. A cana-de-açúcar e a questão Ambiental. In: DINARDO-MIRANDA, L. L.; VASCONCELOS, A. C. M. de; ANDRADE LANDELL, M. G. de. Cana-de-açúcar. Campinas: 
Instituto Agronômico, 2008. p. 869-883.

SCHWARTZ, S. B. Como se cria um país. Revista de História da Biblioteca Nacional, ano 8, n.94, p. 22-25, jul. 2013.

SEaD /UFSCAR. Fluxograma do processo de produção do açúcar cristal. Disponível em: <http:// livresaber.sead.ufscar.br:8080/jspui/handle/ 123456789/568 > Acesso em: 03 abr. 2014.

SILVA, D. PICCOLO. Estudo econômico do período de duração da safra de cana-de-açúcar na produção de açúcar e álcool para usinas de médio porte da região centro-sul do Brasil. $185 \mathrm{f}$. Dissertação (Mestrado) - Escola de Engenharia Mauá do Centro Universitário do Instituto Mauá de Tecnologia, São Caetano do Sul, 2007.

SOCIEDADE BENEFICENTE ISRAELITA BRASILEIRA. Sal, açúcar e outros ingredientes do dia-a-dia. Jan., 2007. Disponível em: <http:// www.einstein.br/einstein-saude/nutricao/Paginas/salacucar-temperos-e-oleos.aspx > Acesso em: 12 mar. 2014.

SOUZA, J. S. I. de. (Coord). Enciclopédia Agrícola Brasileira. São Paulo: Edusp. v. 1, 1995.

TAMBELLINI, C. A. Evaporação e Cozimento. Revista Opiniões, n. 6, p. 26, out./dez. 2005.

TFOUNI, S. A.V.; VITORINO, S. H. P.; TOLEDO, M. C. F. Efeito do processamento na contaminação da cana-de-açúcar e derivados por hidrocarbonetos policíclicos aromáticos. Ciência e
Tecnologia de Alimentos, v. 27, n. 1, p.76-82, 2007.

THEODORO, A. D. Expansão da cana de açúcar no Brasil: ocupação da cobertura vegetal do cerrado. 62 p. Monografia (Graduação) Faculdade de Tecnologia de Araçatuba, Araçatuba, 2011.

TORLONI M.R.; et al. O uso de adoçantes na gravidez: uma análise dos produtos disponíveis no Brasil, Rev. Brás. Ginecologia e Obstetrícia, v. 29, n. 5, p. 267-275, maio 2007.

TORRES, R. C. Estudo do processo de cristalização do açúcar: modelagem e estratégias de controle. 122 f. Dissertação (Mestrado) Universidade Federal de São Carlos, São Carlos, 2007.

TOZETTO A.; DEMIATE I.M.; NAGATAN.; Análise exploratória de adoçantes de mesa via espectroscopia do infravermelho (FTIR) e análise por componentes principais (ACP), Ciênc. Tecnol. Aliment. v. 27, n. 4, p. 723-728, out./dez. 2007.

YARAK, A. Açúcar: um grande vilão da saúde. Maio, 2012. Disponível em: <http:// veja.abril.com.br/noticia/saude/acucar-o-grandevilao-da-sua-saude> Acesso em: 15 mar. 2014.

ZANINI R.V.; ARAÚJO C.L.; MESA J.M.; Utilização de adoçantes dietéticos entre adultos em Pelotas, Rio Grande do Sul, Brasil: um estudo de base populacional, Cad. Saúde Pública, v. 27, n.5, p. 924-934, maio 2011.

RECEBIDO EM 17/1/2014

ACEITO EM 2/7/2014 